\title{
Determinants of Severe Acute Malnutrition Among 6-59 Months' Children at Dubti Referral Hospital, Afar Agro-Pastoralist Region North Eastern Ethiopia, 2018
}

Ibrahim Hussein Ali ( $\nabla$ raagali99.giddisa@gmail.com )

Samara University https://orcid.org/0000-0002-9759-4452

Mohammed Jemal

afar health office

Abel Gebre

samara university

Research

Keywords: Determinants, Case-Control Study, Malnutrition, Severe Acute, Afar, Dubti

Posted Date: June 22nd, 2020

DOI: https://doi.org/10.21203/rs.3.rs-35191/v1

License: (c) (1) This work is licensed under a Creative Commons Attribution 4.0 International License.

Read Full License 


\section{Abstract}

Background: Severe acute malnutrition(SAM) is one of the major public health problems in developing countries including Ethiopia specifically in Afar having an overwhelming consequence on the survives of several children under five-years of age. This study intends to identify the determinants of SAM among 659 months of children at Dubti referral hospital, Afar Regional State, Ethiopia

Methods: An institution-based unmatched case-control study was conducted in Dubti referral Hospital from March 1 to May 15, 2018. The sample size was calculated using Epi-Info ${ }^{{ }^{T M}}$ version 7.2.2.6 Statistical software. Using cases-control (1:2), the total sample size was 297(cases 99, controls 196). A systematic random sampling technique was used, data were collected using interviewer-administered structured questionnaire, entered in Epi-info ${ }^{\mathrm{TM}}$, and analyzed using SPSS 21 version using binary logistic regression, with $\mathrm{P}<0.05$ considered significant.

Result: The response rate was $100 \%$ (297), mean age of the cases and controls was 14.8 months (SD \pm 7.9) and 26.9 months (SD \pm 15.9 ), respectively. Of the participants, $58.58 \%$ were male, $85.4 \%$ were Muslim, and $65.65 \%$ were of Afar ethnicity. SAM was significantly associated with children aged 6-11 months and 12-23 months adjusted odds ratio $(A O R)=4.3,95 \% \mathrm{Cl} 3.64-6.73,11.2,95 \% \mathrm{Cl} 7.89-14.5)$, respectively. Rural residences $(A O R=2.8,95 \% \mathrm{Cl} 2.62-5.73)$, and low monthly family income $(<\$ 30)$ (AOR=3.8, 95\% Cl 2.97-4.87) were independent predictors of SAM. This study revealed low ANC visits (32.2\%), low exclusive breastfeeding practices (34.9\%), and low vaccination coverage (29.6\%).

Conclusion: Children aged 12-23 months, rural dwellers, and low monthly family income $(<\$ 30)$ were identified as independent predictors of SAM. This study revealed low ANC visits, low exclusive breastfeeding practice, and low immunization coverage. Hence, cooperative efforts are needed to increase promotion of enhanced child caring practices specifically, child and maternal feeding practices, and ANC follow up and vaccination practice.

\section{Introduction}

Child severe acute malnutrition(SAM) remains to be an important public health problem in an unindustrialized nation-state. Globally, there were 165 million stunted, 99 million underweight, and 51 million severe acute malnutrition children by year 2012. It kills 3.1 million under-five children every year [1-2]. Under-five children are the most susceptible age group for malnutrition [3]. Malnutrition at the early stages of life can increase risk infections, morbidity, and mortality, together with decreased mental and cognitive development. The effect of child malnutrition is long-lasting and goes beyond childhood [4]. For example, malnutrition throughout a timely age loses learning attainment and work productivity and increases the possibility of protracted diseases in advanced stages $[1,2,5]$. 
Malnutrition is the major cause of illness and death among under-five children in Ethiopia [6]. The rate of malnutrition among under-five children in the country is among the highest in the world and Sub-Saharan Africa [7]. Moreover, malnutrition is the underlying cause for three-fifth of child deaths in the country $[1,8]$. According to the 2014 Ethiopian Mini Demographic and Health Survey (EMDHS) report, 42\%, 26.7\%, and $9 \%$ of under-five children were stunted, underweight, and wasted, respectively, [1]. The problem is even worse in rural areas. For instance, the prevalence of underweight and stunting among rural children was $27 \%$ and $42 \%$ compared with only $13 \%$ and $24 \%$ among urban children, respectively, $[1,5]$.

The planning of an appropriate intervention requires knowledge of the extent and underlying causes of the problem. To this end, very few studies have been conducted regarding childhood malnutrition in rural Ethiopia [1]. All of them were small-scale surveys limited to particular regions of the country $[1,8]$. Later, they did not provide a complete representation of the magnitude of the problem at the nation-state level. Moreover, these studies used the conventional indicators of nutritional status to measure the prevalence of malnutrition in under-five children [1]. However, a number of studies have pointed out that the use of conventional indicators provides only the categorization of children into the general categories of malnutrition and does not determine the inclusive occurrence of malnutrition related to several catastrophes. Accordingly, these indicators underestimate the occurrence of malnutrition due to the possible similarity of children into various types of anthropometric catastrophe [1].

Therefore, in this study, we used a recently developed and relatively robust alternative indicator of malnutrition, the composite index of anthropometric failure (CIAF) to determine the risk factors of malnutrition among under-five children in Dubti Hospital, Afar region, Ethiopia.

\section{Methods And Materials}

\section{Study area, design, and period}

The study was conducted at the Dubti referral hospital, which was found in the awsa zone. The awsa zone is one of the five administrative zones of the Afar national regional state and is located north east to $594 \mathrm{~km}$ of Addis Ababa. It has an estimated population of 55,519 as projected from the $2007 / 2008$ census. An institution-based unmatched case-control study was conducted from March 1 to May 15, 2018.

\section{Source and study population}

Children aged six up to fifty-nine months who were attending Dubti referral hospitals for different health care concerns throughout the study period were the source population. Randomly selected children aged six up to fifty-nine months were the study population. Those children who had severe acute malnutrition Mid-Upper Arm Circumference (MUAC) $<11.5 \mathrm{~cm}$, if there was edema for cases and who had no malnutrition a MUAC $\geq 12.5 \mathrm{~cm}$, there was no edema) for controls with their corresponding mothers'/care takers, respectively. 


\section{Inclusion criteria}

Children aged 6-59 months who visited or were admitted to the hospitals and who had severe acute malnutrition (MUAC $<11.5 \mathrm{~cm}$ or with bilateral pitting edema of nutrition origin), with their caretakers/mothers who gave informed consent were recruited into the study as cases. Controls included children aged 6-59 months, and attending to the hospitals (MUAC $\geq 12.5$, without bilateral pitting edema of nutritional origin) with their mothers/caretakers, who gave informed consent.

\section{Exclusion criteria}

Children who had physical deformities (children born without hands due to congenital deformities, wounded, and burned hands) that make anthropometric measurements inconvenient were excluded from the study.

\section{Selection of cases}

Children aged 6-59 months who were admitted during the data collection period were allocated to hospital depending on the previous month's severe acute malnourished children flow. Cases were children with a diagnosis of severe acute malnutrition with MUAC of $<11.5 \mathrm{~cm}$ or bilateral pitting edema of nutritional origin.

\section{Selection of controls}

Controls were children without malnutrition a MUAC of $\geq 12.5 \mathrm{~cm}$, without bilateral pitting edema of nutritional origin, and were selected from the same hospital from which cases were selected.

\section{Sample size determination}

The sample size was calculated using Statcalc of application of Epi-Info ${ }^{\mathrm{TM}}$ version 7.2.2.6 Statistical software. Using one to two ratios (1:2) of cases to controls, percentage of controls exposed $70 \%$ and cases exposed $85 \%$ and odds ratio 2.42 in Dubti district with an assumption of $95 \%$ confidence interval and power $80 \%$. So the cases were 99 , controls were 198 , and the total sample size was 297 .

\section{Sampling technique}

Only one referral hospital found in the Afar region was included, and 98 children who were severely acute malnourished and 196 well-nourished admitted/visited to the hospitals for other health care issues were selected. Children aged 6-59 months with severe acute malnutrition were allocated to the hospital depending on the average previous month's severe acutely malnourished children admission to the Hospitals.

From previous months on average, 112 children with cases of severe acute malnutrition were reported, and during the three months, there were 412 children with cases of severe acute malnutrition at Dubti hospital. Depending up on this, 98 cases and 196 controls were selected from the Dubti referral Hospital 
and a systematic random sampling technique was used to select each $2^{\text {nd }}$ child from 412 children. The controls were selected as quickly as cases were selected from the same hospital.

\section{Data collection instruments and procedures}

Data were collected using a pre-tested, structured, and interviewer and anthropometric measurements (particularly MUAC) administered questionnaire adapted from the Ethiopian Demographic and Health Survey [5]. The adapted questionnaire was once modified and contextualized to suit the local situation and the research objective. The questionnaire was initially prepared in English and then translated into Afar'af and back to English to check for uniformity. The Afar'af model of the questionnaire was used to collect the data. Data were collected through two diploma nurses. The data collectors were trained for one day through the principal investigator on the study tool, consent procedure, how to interview and data collection method. The training included briefings of the study objectives, methods of selecting the study participants, a thorough review of the questionnaire, interviewing techniques, direction as to how to fill the structured questionnaire, and how to make certain high-quality data collection. At the end of the theoretical training, participants of the training were taken to areas where they could practice administering the questionnaire and taking anthropometric measurements. Inter- and intra-observer variations were monitored, especially for anthropometric measurements. This pre-testing also served to evaluate the study tool, estimate the average time to administer a questionnaire, and made corrections and additions before finalizing the instrument for actual the study. Once a case was found and his or her caregivers interviewed, two controls meeting the criteria were selected and their caregivers interviewed. To discover the retrospective morbidity of children, mothers were asked about any occurrence of sickness in the course of the previous two weeks.

\section{Variables of the study}

MUAC was measured with a standard MUAC tape on the upper left arm. After locating the mid-point for dimension between the end of the shoulder (acromion) and the tip of the elbow (olecranon), this point was then marked. The arm was then made to hang freely, and MUAC was measured at the marked midpoint. Sociodemographic variables, economic status, maternal characteristics, child characteristics and caring practices, health-related characteristics, and community factors were considered as independent variables.

\section{Data quality control}

The data collectors and supervisors were trained for one day and standardized specifically in the suitable filling of questionnaire, and the practice of the measurement system the armband/tape in order to decrease inter and intra-observer errors. Data quality was measured through piloting a pretest on $5 \%$ of the samples in Aysaita Hospital before the real study, and significant changes were made at the beginning of the results. Data collectors were combined throughout data collection to confirm the quality of the data. Data collection was supervised by the primary investigator. Each questionnaire was managed and revised for completeness and logical consistency. The comprehensiveness of the questionnaire was 
also checked before data entry. Anthropometric measurement (MUAC) of children used to be executed via trained data collectors the use of standard procedures.

\section{Data processing and analysis}

The data were checked for comprehensiveness, coded, and entered into a computer using SPSS for Windows version 21 and then corrected, prepared, managed, and analyzed. Descriptive analysis was used to describe the percentages and number of distributions of the respondents via socio-demographic features and other appropriate variables in the study. In order to consider the relationship of independent variables with severe acute malnutrition, both bivariate and multivariate analyses were used. Bivariate analysis was done on the independent variables, and their proportions and crude odds ratio were calculated compared to the outcome variable to ascertain the factors that were related with child severe acute malnutrition. Hosmer-Lemeshow goodness-of-fit was used to check for model fitness. Variables that showed a relationship with the independent variable in the bivariate analysis with $p$ value $<0.05$ were entered into the final multivariable logistic regression to control for possible confounders. Adjusted odds ratio (AOR) along with 95 \% confidence interval was estimated to calculate the strength of the association, and a $P$ value $<0.05$ was measured to declare the statistical significance in the multivariable analysis in this study.

\section{Ethics approval}

Before engaging in this study, all participants gave verbal informed consent. The research was approved by the Scientific Review Committee and the Ethical Review Committee of Samara University. Confidentiality has been ensured, and no personal details are reported in this paper.

\section{Results}

The response rate was 100\% (99 cases and 198 controls) were participated. The mean age of the cases and controls was 14.8 months (SD \pm 7.9$)$ and 26.9 months (SD \pm 15.9$)$, respectively. Of the cases and controls, 56 (32.2) and 118 (68) were males, respectively. The majority of cases 81 (81.8\%) and controls $169(85.4 \%)$ were Muslims. Concerning the ethnicity of participants, $63(32.3 \%)$ of cases and 132 (76.7\%) controls were Afar, 22 (36.7\%) of cases, 38 (63.3\%) controls were Amhara, 8 (33.3\%) of cases, and 16 $(66.7 \%)$ controls were Tigray (Table 1$)$. 
Table 1

Sociodemographic characteristics of cases and controls from Dubti Hospital, Afar

Regional State, Northeast Ethiopia, May 2018 (cases $=99$ and controls = 196).

\begin{tabular}{|c|c|c|c|}
\hline Variable & Profile & Cases, N (\%) & Control, N (\%) \\
\hline \multirow[t]{3}{*}{ Age of child } & 6 to 11 & $20(35.1)$ & $37(64.9)$ \\
\hline & 12 to 23 & $29(28.2)$ & $74(71.8)$ \\
\hline & 24 to 59 & $50(36.5)$ & $87(63.5)$ \\
\hline \multirow[t]{2}{*}{ Sex of child } & Male & $56(32.2)$ & $118(67.8)$ \\
\hline & Female & $43(35.0)$ & $80(65.0)$ \\
\hline \multirow[t]{4}{*}{ Birth order } & 1st child & $25(30.5)$ & $57(69.5)$ \\
\hline & 2nd to 3rd & $48(29.4)$ & $115(70.6)$ \\
\hline & 4th to 5 th & $22(61.1)$ & $14(38.9)$ \\
\hline & 6th and above & $4(25.0)$ & $12(75.0)$ \\
\hline \multirow[t]{2}{*}{ Residence } & Urban & $72(31.7)$ & $155(68.3)$ \\
\hline & Rural & $27(38.6)$ & $43(61.4)$ \\
\hline \multirow[t]{4}{*}{ Educational level } & Illiterate & $53(36.8)$ & $91(63.2)$ \\
\hline & Primary & $18(34.6)$ & $34(65.4)$ \\
\hline & Secondary & $9(20.9)$ & $34(79.1)$ \\
\hline & Higher education & $19(32.8)$ & 39 (67.2) \\
\hline \multirow[t]{4}{*}{ Ethnicity } & Afar & $63(32.3)$ & $132(67.7)$ \\
\hline & Amhara & $22(36.7)$ & $38(63.3)$ \\
\hline & Tigray & $8(33.3)$ & $16(66.7)$ \\
\hline & Others & $6(33.3)$ & $12(66.7)$ \\
\hline \multirow[t]{4}{*}{ Religion } & Muslim & $81(32.4)$ & $169(67.6)$ \\
\hline & Orthodox & $14(34.1)$ & $27(65.9)$ \\
\hline & Protestant & $1(50)$ & $1(50)$ \\
\hline & Others & $3(75)$ & $1(25)$ \\
\hline \multirow[t]{2}{*}{ Monthly income } & Less than 1000 & $36(66.7)$ & $18(33.3)$ \\
\hline & Greater than or equal to 1000 & $63(25.9)$ & $180(74.1)$ \\
\hline
\end{tabular}


Less than one-third $29.1 \%$ of cases and approximately two-third $70.9 \%$ of the controls had initiated breastfeeding within an hour of birth. Concerning the exclusive breast feeding duration, $34.9 \%$ of cases and $65.1 \%$ of controls provided exclusive breastfeeding, while $23.1 \%$ of cases and $76.9 \%$ did not provide exclusive breastfeeding. Of the $29.6 \%$ cases, $70.4 \%$ were vaccinated, while $78.3 \%$ case and $21.7 \%$ controls were not vaccinated (Table 2).

Table 2

Nutritional feeding practices of cases and controls from Dubti Hospital, Afar Regional State, Northeast Ethiopia, May 2018 (cases $=99$ and controls = 196).

\begin{tabular}{|c|c|c|c|}
\hline Variable & Profile & Cases, N (\%) & Control, N (\%) \\
\hline \multirow[t]{3}{*}{ BF initiation time } & Immediate after birth & $3(75)$ & $1(25)$ \\
\hline & Within $1 \mathrm{hr}$ & $53(29.1)$ & $129(70.9)$ \\
\hline & After 1 hour & $23(48.9)$ & $24(51.1)$ \\
\hline \multirow[t]{2}{*}{ Colostrum } & Yes & $77(32)$ & $164(68)$ \\
\hline & No & $22(39.3)$ & $34(60.7)$ \\
\hline \multirow[t]{2}{*}{ EBF } & Yes & $90(34.9)$ & $168(65.1)$ \\
\hline & No & $9(100)$ & $30(76.9)$ \\
\hline \multirow[t]{4}{*}{ Frequency of BF per day } & 1 & $5(23.8)$ & $16(76.2)$ \\
\hline & $2-3$ time & $82(34.7)$ & $154(65.3)$ \\
\hline & $4-5$ times & 7 (33.3) & $14(66.7)$ \\
\hline & Greater than 5 & $5(26.3)$ & $14(73.7)$ \\
\hline \multirow[t]{2}{*}{ Diarrhea episode } & Yes & $57(49.1)$ & $59(50.9)$ \\
\hline & No & $42(23.2)$ & $139(76.8)$ \\
\hline \multirow[t]{2}{*}{ Immunization } & Yes & $81(29.6)$ & $193(70.4)$ \\
\hline & No & $18(78.3)$ & $5(21.7)$ \\
\hline \multirow[t]{2}{*}{ Vitamin A rich meal intake } & Yes & $17(17.3)$ & $81(82.7)$ \\
\hline & No & $82(41.2)$ & $117(58.8)$ \\
\hline
\end{tabular}

\section{Health service utilization of mother's cases and controls}

The majority of the study participant's mothers $76(32.2 \%)$ of case and $160(67.8 \%)$ of the controls had an antenatal care visit. Among these $25(35.7 \%)$ cases and $45(64.3 \%)$ only one visit, $22(47.8 \%)$ cases and $24(52.2 \%)$ two visits, $14(51.9 \%)$ case and $13(48.1 \%)$ controls three visits and $15(16.1 \%)$ cases and 
$76(83.9 \%)$ controls had more than three visits, respectively. Of $70(29 \%)$ cases and $171(71 \%)$ had postnatal care visits, while $29(51.8 \%)$ cases and 27 (48.2\%) controls had no postnatal care (Table 3).

Table 3

Health service utilization of cases and controls from Dubti Hospital, Afar Regional State, Northeast Ethiopia, May 2018 (cases: $=99$ and controls: $=196)$.

\begin{tabular}{|llll|}
\hline Variable & Profile & Cases, N (\%) & Control, N (\%) \\
\hline ANC visit & Yes & $76(32.2)$ & $160(67.8)$ \\
\cline { 2 - 4 } & No & $23(37.7)$ & $38(62.3)$ \\
\hline ANC visit frequency & 1 visit & $25(35.7)$ & $45(64.3)$ \\
\cline { 2 - 4 } & 2 visit & $22((47.8)$ & $24(52.2)$ \\
\cline { 2 - 4 } & 3 visit & $14(51.9)$ & $13(48.1)$ \\
\cline { 2 - 4 } & Above 3 visit & $15(16.1)$ & $76(83.9)$ \\
\hline Nutritional counsel & Yes & $69(30.7)$ & $156(69.3)$ \\
\cline { 2 - 4 } & No & $30(42.9)$ & $40(57.1)$ \\
\hline PNC visit & Yes & $70(29.0)$ & $171(71.0)$ \\
\cline { 2 - 4 } & No & $29(51.8)$ & $27(48.2)$ \\
\hline ANC = antenatal care, PNC= postnatal care & \\
\hline
\end{tabular}

\section{Environmental health and sanitation characteristics of cases and controls}

Of the sources of water, $72(30.69 \%)$ case and 161 (69.1\%) controls from the pipe, despite the fact that 13 $(38.2 \%)$ cases and $21(61.8 \%)$ controls from the unprotected well were accessing water. With regard to toilets availability, $85(33.1 \%)$ case and $172(66.9 \%)$ had toilets, while $13(33.3 \%)$ cases and $26(66.7 \%)$ had not toilets. Concerning hand washing after latrine use, 70 (32.4\%) cases and $146(67.6)$ controls washing their hands after latrine use, while 29 (35.8\%) cases and 52 (64.2\%) controls were not washing their hands after using latrine (Table 4). 
Table 4

Environmental factors of cases and controls from Dubti hospital, Afar Regional State, Northeast Ethiopia, May 2018 (cases $=99$ and controls $=196$ ).

\begin{tabular}{|c|c|c|c|}
\hline Variable & Profile & Cases, N (\%) & Control, N (\%) \\
\hline \multirow[t]{6}{*}{ Source of water } & Protected well & $7(35)$ & $13(65.0)$ \\
\hline & Unprotected well & $13(38.2)$ & $21(61.8)$ \\
\hline & Car & $2(50)$ & $2(50)$ \\
\hline & Pipe & $72(30.69)$ & $161(69.1)$ \\
\hline & Piped into dwelling & $1(50)$ & $1(50)$ \\
\hline & Others & $2(100)$ & $4(100)$ \\
\hline \multirow[t]{2}{*}{ Toilet availability } & Yes & $85(33.1)$ & $172(66.9)$ \\
\hline & No & $13(33 . .3)$ & $26(66.7)$ \\
\hline \multirow[t]{5}{*}{ Method of garbage disposal } & Open field & $24(51.1)$ & $23(48.9)$ \\
\hline & In a pit & $16(43.2)$ & $21(56.8)$ \\
\hline & Composting & $3(60.0)$ & $2(40.0)$ \\
\hline & Burning & $55(26.6)$ & $152(73.4)$ \\
\hline & Other & $1(100.0)$ & $0(0.0)$ \\
\hline \multirow[t]{2}{*}{ Hand washing after latrine use } & Yes & $70(32.4)$ & $146(67.6)$ \\
\hline & No & $29(35.8)$ & $52(64.2)$ \\
\hline
\end{tabular}

\section{Factors Associated with Acute Malnutrition}

According to multivariate statistical analysis, age of the children, sex of the children, current residence of the children, and monthly income of the family of children were statistically associated with acute malnutrition independent of other factors. Based on this multivariate statistical analysis result, children 6-11 months and 12-23 months were 4 times and 11 times, severe acute malnourished than children 24-59 months, AOR with $\mathrm{Cl} 4.3(3.64-6.73)$, and 11.2(7.89-14.5), respectively. On the subject of their current residence, children in rural residences were 3 times more severely acute malnourished than urban dwellers (AOR $=2.8,95 \% \mathrm{Cl} 2.62-5.73)$. Concerning monthly income of the family, those who had less than 30-dollar per month were 4 times more severe acute malnourished than the family those who had more than 30-dollar per month (AOR $=3.809,95 \% \mathrm{Cl} 2.97-4.87)$ (Table 5). 
Table 5

Multivariable analysis of determinants of SAM among 6 to 59 months' children at Dubti Hospital of Afar Ethiopia, May $2018(\mathrm{~N}=297)$

\begin{tabular}{|c|c|c|c|c|}
\hline Variables & $\begin{array}{l}\text { Cases N } \\
(\%)\end{array}$ & $\begin{array}{l}\text { Control N } \\
\text { (\%) }\end{array}$ & Crude OR(95\%Cl) & $\begin{array}{l}\text { Adjusted } \\
\text { OR(95\%Cl) }\end{array}$ \\
\hline \multicolumn{5}{|l|}{ Child age (months) } \\
\hline $6-11$ & $20(35.1)$ & $37(64.9)$ & $3.94(2.25-5.97)$ & $4.3(3.64-6.73)$ \\
\hline $12-23$ & $29(28.2)$ & 74(71.8) & $7.2(4.9-8.4)$ & $11.2(7.89-14.5)$ \\
\hline $24-59$ & $50(36.5)$ & $87(63.5)$ & 1 & 1 \\
\hline \multicolumn{5}{|l|}{ Residence } \\
\hline Rural & 72(31.7) & $155(68.3)$ & $\begin{array}{l}3.619(2.329- \\
4.173)\end{array}$ & $2.8(2.62-5.73)$ \\
\hline Urban & $27(38.6)$ & $43(61.4)$ & 1 & 1 \\
\hline \multicolumn{5}{|l|}{ Sex } \\
\hline Male & $56(32.2)$ & $118(67.8)$ & $2.3(1.87-3.2)$ & $3.4(2.97-4.87)$ \\
\hline Female & $43(35.0)$ & $80(65.0)$ & 1 & 1 \\
\hline \multicolumn{5}{|l|}{ Income } \\
\hline$<\$ 30$ & $36(66.7)$ & 18(33.3) & $1.5(1.3-1.77)$ & $\begin{array}{l}3.809(2.079- \\
6.979)\end{array}$ \\
\hline$>\$ 30$ & $63(25.9)$ & $180(74.1)$ & 1 & 1 \\
\hline \multicolumn{5}{|l|}{ Diarrhea } \\
\hline $\begin{array}{l}\text { Diarrhea in the last } 2 \\
\text { weeks }\end{array}$ & $54(49.1)$ & $59(50.9)$ & $0.13(0.02-0.27)$ & $\begin{array}{l}0.514(0.289- \\
0.912)\end{array}$ \\
\hline Non-Diarrheic & $42(23.2)$ & 139(76.8) & 1 & 1 \\
\hline \multicolumn{5}{|l|}{ Vitamin A } \\
\hline Not Taken Vitamin A & $17(17.3)$ & $81(82.7)$ & $0.32(0.179-0.576)$ & $\begin{array}{l}0.447(0.246- \\
0.813)\end{array}$ \\
\hline Taken Vitamin A & $63(25.9)$ & $117(58.8)$ & 1 & 1 \\
\hline
\end{tabular}

\section{Discussion}

Children age was one of the determinants of severe acute malnutrition. Children aged 6-11 months and 12-23 months were 4 and 11 times more likely to be severely acute malnourished than those aged 2459 months, respectively. This study is similar to a study done in India 12 to 23 months of children with severe acute malnutrition than the older one [9]. This result is also related to a study conducted in 2014 in Dubti district, in which children aged 6-23 were acutely malnourished than children aged 24-59 except 
for slight differences. This study shows that children 12-23 months were 11 times more likely acute malnourished, while the study conducted in Dubti district showed 10 times more likely to be severely acute malnourished [10]. This difference could be because several clients might visit hospitals than district health centers [10].

This study proved that the place of current residence was strongly associated with severe acute malnutrition, and children living in rural areas were 3 times more likely to be severely acutely malnourished than living in urban areas $(A O R=2.8,95 \% \mathrm{Cl} 2.62-5.73)$. This finding was consistent with a study conducted in Dubti district in 2014, which revealed that children living in rural kebeles twice as likely to be severely acutely malnourished [10].

Household monthly income had a revealed significant association with severe acute malnutrition. The likelihood of the child severely acutely malnourished increased when households' monthly income was found to a smaller amount of 30 dollars per month. This confirms that the household monthly income was inversely related to severe acute malnutrition. This result is similar to a study done in Kersa woreda Oromia region [11], and other studies conducted in different parts of the world [5, 12]. Based on this study from the study participants, $53(29.1 \%)$ of cases and $129(70.9 \%)$ controls initiated breastfeeding before one hour while $23(48.9 \%)$ cases and $24(51.1 \%)$ controls initiated breastfeeding after one hour. Regarding colostrum, $77(32 \%)$ cases and $164(68 \%)$ of controls of mothers were provided to their infants. Concerning the exclusive breast feeding duration, $90(34.9 \%)$ of cases and $168(65.1 \%)$ controls were provided exclusive breastfeeding, while $9(23.1 \%)$ of cases and $30(76.9 \%)$ were not provided exclusively breastfed. Regarding the frequency of breastfeeding per day $82(34.7 \%)$ of case and 154 $(65.3 \%)$ of the controls were breastfeeding $2-3$ times per day at the same time as 7 (33.3\%) cases and 14 (66.7\%) were breastfeeding 4-5 times per day. This study better than the case-control study done at the Gondar University teaching Hospital from July 2005 to April 2006. Lack of exclusive breast feeding for the first six months of age was more common in the cases 49 (48.0\%) than in the controls 24 (23.5\%) [5]. The difference might be the time gap of years and geographical differences.

\section{Conclusion}

Children aged 12-23 months, rural dwellers, and low monthly family income $(<30)$ were identified as independent predictors of SAM. This study revealed low ANC visits, low exclusive breastfeeding practice, and low immunization coverage. Hence, cooperative efforts are needed to increase promotion of enhanced child caring practices specifically, child and maternal feeding practices, and ANC follow up and vaccination practice.

\section{Abbreviations}

AIDS Acquired Immunodeficiency Syndrome

ANC Antenatal Care 
BCG Bacille Calmette-Guérin

BMI Body Mass Index

CDC Centers for Disease Control and Prevention

CSA Central Statistical Agency

DPT Diphtheria, Pertussis [whooping cough] and Tetanus

EDHS Ethiopia Demographic and Health Survey

FMOH Federal Ministry of Health

HEW Health Extension Workers

HIV Human Immunodeficiency Virus

MCH Maternal and Child Health

MDG Millennium Development Goal

MUAC Mid-Upper Arm Circumference

NGO Non-Governmental Organization

NNP National Nutrition Program

PSNP Productive Safety Net Program

SD Standard Deviation

TSF Targeted Supplementary Food

VAD Vitamin A Deficiency

WHO World Health Organization

\section{Declarations}

\section{Ethics approval and consent to participate}

Before engaging in this study, all participants gave verbal informed consent. The research was approved by the Scientific Review Committee and the Ethical Review Committee of Samara University. Confidentiality has been ensured, and no personal details are reported in this paper. 
Not applicable

\section{Availability of data and materials}

The dataset that was used in this study is available with the corresponding author with reasonable request at any time.

\section{Funding}

The study was not funded partially or fully by anybody.

\section{Competing interests:}

The authors declare that they have no competing interests.

\section{Authors' contributions}

MJ coded, cleaned, entered, and analyzed the data. AG interpreted and revised the data, and IA wrote the report and organized the manuscript. All authors have read and approved the final manuscript.

\section{Acknowledgments}

Our gratitude extends to Samara University, Dubti referral hospital, data collectors, and study participants.

\section{Authors' information}

\section{Affiliations}

1. Department of Public Health, College of Medicine and Health Sciences, Samara University, Samara, Ethiopia

- Ibrahim Hussein Ali (Mph)

2. Afar Regional Health Office, Samara, Ethiopia

- Mohammed Jemal (Mph)

3. Department of Public Health, College of Medicine and Health Sciences, Samara University, Samara, Ethiopia

- Abel Gebre (Mph)

\section{References}

1. Endris N. Asefa H, Dube L Prevalence of Malnutrition and Associated Factors among Children in Rural Ethiopia. BioMed Research International. 2017;2017:6587853..

2. Black RE. Victora CG, Walker SP. Bhutta ZA, Christian P. de Onis M, et al. Maternal and child undernutrition and overweight in low-income and middle-income countries. The Lancet. 2013;382(9890):427 - 51.. 
3. Nigatu G, Assefa Woreta S, Akalu TY, Yenit MK. Prevalence and associated factors of underweight among children 6-59 months of age in Takusa district, Northwest Ethiopia Int J Equity Health 2018;17(1):106.

4. Martins VJB, Toledo Florêncio TMM, Grillo LP, do Carmo P Franco M, Martins PA, Clemente APG, et al. Long-lasting effects of undernutrition. Int J Environ Res Public Health. 2011;8(6):1817-46. .

5. Central Statistical Agency. Ethiopia Mini Demographic and Health Survey 2014. Addis Ababa, Ethiopia: CSA; 2014...

6. Wagnew F, Tesgera D, Mekonnen $\mathrm{M}$, Abajobir AA. Predictors of mortality among under-five children with severe acute malnutrition, Northwest Ethiopia: an institution based retrospective cohort study. Archives of Public Health 2018;76(1):64.

7. Wete AT. Zerfu TA, Anbese AT. Magnitude and associated factors of wasting among under five orphans in Dilla town, southern Ethiopia: 2018: a cross-sectional study. BMC Nutrition. 2019;5(1):33.

8. Gebre A, Reddy PS, Mulugeta A, Sedik Y, Kahssay M. Prevalence of Malnutrition and Associated Factors among Under-Five Children in Pastoral Communities of Afar Regional State, Northeast Ethiopia: A Community-Based Cross-Sectional Study. Journal of Nutrition and Metabolism. 2019;2019:9187609.

9. Singh K. Badgaiyan N, Ranjan A. Dixit HO, Kaushik A. Kushwaha KP, et al. Management of children with severe acute malnutrition: Experience of Nutrition Rehabilitation Centers in Uttar Pradesh, India. Indian Pediatrics. 2014;51(1):21 - 5..

10. Seid A, Seyoum B, Mesfin F. Determinants of Acute Malnutrition among Children Aged 6-59 Months in Public Health Facilities of Pastoralist Community, Afar Region, Northeast Ethiopia: A Case Control Study. Journal of nutrition and metabolism. 2017;2017:7265972-..

11. Egata G. Berhane Y, Worku A. Predictors of acute undernutrition among children aged 6 to 36 months in east rural Ethiopia: a community based nested case - control study. BMC Pediatrics. 2014; 14(1):91..

12. Bachou H. Tumwine JK, Mwadime RKN, Tylleskär T. Risk factors in hospital deaths in severely malnourished children in Kampala, Uganda. BMC Pediatrics. 2006;6(1):7.. 